\title{
The Challenge of Informality: Perspectives on China's Changing Labour Market
}

\author{
Sarah Cook
}

Labour is only another name for a human activity which goes with life itself, which in its turn is not produced for sale but for entirely different reasons ... the alleged commodity 'labour power' cannot be shoved about, used indiscriminately or even left unused, without affecting also the human individual who happens to be the bearer of this peculiar commodity.

(Polanyi 1957: 75, 76)

\begin{abstract}
1 Introduction: towards a labour market in China China's transformation from a closed, planned economy to the leading global manufacturer of export products has entailed a restructuring of economic and social organisation on a massive scale. A central feature of this process has been the recommodification of labour. The 'cradle to grave' protections afforded to urban employees through the iron rice bowl have been dismantled. Rural producers, always more exposed to the uncertainties of nature and the extractive demands of an industrialising state, were nonetheless provided with basic security through the collective organisation of production and a guaranteed right to land. This system of economic organisation, while institutionalising inequalities between urban state sector employees and others (particularly rural residents) provided basic guarantees of economic security and access to minimal social provisioning. Commercialisation and decollectivisation have increased the exposure of rural producers to markets as new and volatile sources of risk, while the position of the former urban 'labour aristocracy' has been reduced to that of workers' selling a commodity - labour - in an increasingly competitive market.
\end{abstract}

Through these rapid changes, labour has re-emerged as an important, if not the main, asset of the working poor, providing an important link between economic growth and distributional or welfare outcomes, particularly for lower income groups. A common assumption (challenged by articles in this IDS Bulletin) is that reforms aimed at securing free and flexible labour markets should generate labour intensive growth trajectories necessary for poverty reduction. While China may appear to fit this pattern - having seen rapid growth, with both an expansion of labour intensive production and poverty reduction - it is nonetheless questionable whether the labour elasticity of growth has been sufficiently high, pro-poor or sustainable (see Rodgers, this IDS Bulletin). Furthermore, job creation alone may not be enough: the nature and quality of jobs is also critical for generating pro-poor or equitable development outcomes.

What is clear in the Chinese case is that the conditions under which labour is supplied, exchanged and rewarded in this emerging 'market' have changed beyond recognition since the start of economic reform. Negotiations over the value of, or returns to, labour, and the distribution of these gains; the role of the state in protecting workers or incentivising employers; and the restructuring of social security, are some of the elements contributing to a major social transformation, involving protest and struggle over lost entitlements, greater competition for jobs and opportunities, and a re-definition of the role of household, society and state in the reproduction of labour.1

One significant - though under-researched - feature of this transformation is the rise in 'informal' employment. While defining and measuring informal employment, particularly given currently available statistics, is not straightforward, there are a number 
of different angles from which to interpret this aspect of China's changing economy. It is part of the story of structural transformation involving the unprecedented speed of transfer of people out of agriculture into off-farm employment, ${ }^{2}$ and of the emergence of a labour market that appears more closely to approximate a competitive neoclassical model.

This article focuses on the rise of 'informality' in China's employment system; it explores the extent to which conventional labour economic models capture or explain the reality of this 'informalisation' process, and considers the implications for employment and social protection. Connecting with the core questions of this IDS Bulletin, the article explores what drives precariousness of incomes and jobs in the context of China's labour market changes. The article concludes by discussing what this means for research - conceptual, statistical measurement, data collection and empirical analysis - and for policy.

\section{Economic transition and the rise of informal employment}

The notion of informality of employment came late to China. In the 1970s observers described the emergence of a 'second economy' consisting of small enterprises that had managed to survive or revive after the political turmoil of previous decades. This small second economy of informal petty production and exchange existed, largely hidden from the view of outside observers, but operating within limits tolerated by the state. Such activities were sometimes part of the survival strategies of those living at the margins of a tightly controlled society; but were also evidence of nascent entrepreneurship pushing the limits of such controls, and later able to blossom into China's private sector.

During the 1980s, decollectivisation, the emergence of rural industry and related marketing activities, the demand for labour in cities and the gradual loosening of controls on mobility, created a situation where the rural population - no longer governed by the commune - could diversify its income generating activities. The spread of 'free markets' and the greater mobility of farmers able to sell produce to urban residents, alongside rising incomes and the demand for new products, created opportunities for a range of labour use and activities: small food producers, repairs of shoes, bicycles, collection of bottles or other items for recycling, and petty trade, for example, started to proliferate.
Many of these occupations in other contexts would clearly be classified as 'informal'. They typically cover a multiplicity of types of activity - from casual, poorly paid wage labour, to own production, to management of enterprises. Variations exist in ease of entry, capital requirements, competition and access to markets. In the Chinese context, political connections or social networks (guanxi) have also been key determinants of success for private enterprise. However, some activities on which more marginal groups depended were challenged by cheap manufactured products or other substitutes - the repairs of bowls, pots and pans, and other utensils that could be easily replaced by factory output, for example. As Lu Xueyi and his colleagues at CASS have pointed out in their work on social stratification, ${ }^{3}$ the disappearance of some 'jobs' and rapid shifts in occupation or economic activity have contributed to changes in income levels and economic status, and in social stratification.

New and diverse forms of economic activity, on the margins of what was officially sanctioned by the 'plan', rapidly emerged in the shadows created by the withdrawal of the state from some spheres of economic organisation. This can perhaps most clearly be seen in the rise of migration and the occupations into which migrants moved on the fringes of urban society. By placing themselves in these liminal spaces, undertaking jobs in construction, street trading, garbage collection and other less desirable service work rejected by urban workers, the migrants themselves - rather than the work they did - became the 'marginal', informal, even 'illegal', subjects.

While the activities undertaken by migrants and other 'marginal' workers lend themselves to the label of 'informal' according to conventional definitions and conceptualisations, this terminology was not widely applied in China. As elaborated on below, the formal-informal dichotomy was less prominent in the Chinese context than the rural-urban dualism, which structured the types of employment, status, rights and recognition afforded to migrants and their work.

The impetus to the recognition of 'informal' employment as a policy issue in China can be most directly linked to the massive layoffs precipitated by Zhu Rongji's state enterprise reforms from the mid1990s. This radical restructuring created a level of unemployment not previously seen in the People's 
Republic, which in turn generated a political challenge to the stability and legitimacy of the regime. The government responded initially with transitional measures to address the basic needs of those laid-off (xiagang) workers affected directly by restructuring. ${ }^{4}$ It soon became clear, however, that 'high' levels of unemployment would remain a feature of the reformed economy; that many 'working' people were no longer earning enough to provide an acceptable living standard, and that job creation was insufficient to re-employ redundant workers and to absorb new labour force entrants or the 'hidden' unemployed.

In other words, the limit to labour re-commodification became quickly apparent. The state needed to find other mechanisms to protect workers, ensure social reproduction of labour and social provisioning, in order to maintain social stability and uphold the legitimacy of the Party-led state.

In response, the government introduced new types of active labour policies, with massive programmes of skills training, the establishment of 'labour exchanges' to assist workers in finding jobs, and the creation of 'community-based' employment schemes. Many of the new 'jobs' created in this way were short term, part-time and designed as transitional rather than longer term measures - or, in the Chinese terminology - 'flexible' (linghuo). Significantly, this was part of a more fundamental recognition that 'standard' (biaozhun) employment with long-term contracts and social security could not remain the sole or ideal type. Supplementing these labour market measures, a second major strand in the government's response has been the development and expansion of new forms of social insurance to replace those previously provided by the work unit. Initially, transitional measures were put in place to provide benefits to those laid off, while longer-term arrangements were developed (Cook 1999). Contributory pensions, unemployment and health insurance programmes were subsequently introduced for urban employees; these are being expanded to dependents, and in some cases to selfemployed and migrant workers (particularly in the more developed cities such as Shanghai. Social assistance programmes are also being rolled out, the principal one being a means-tested cash transfer programme (the Minimum Living Standard Programme or dibao). ${ }^{5}$ Finally, and most recently a number of new labour laws and policies have been introduced or are under discussion aimed at promoting employment and protecting workers through contracts.

Throughout this structural adjustment process, the state-led terminology was focused on laid-off workers (xiagang zhigong) and re-employment (zai jiuye). The political sensitivity of rising unemployment (shiye) needed to be downplayed; ${ }^{6}$ where laid off workers were unable to get new jobs, this was often blamed on their low 'quality' (suzhi) and unsuitability for work in the new competitive labour market (Cook and Jolly 2000). While many of these workers found what can only be described as 'informal' work to generate incomes, such activities went largely unobserved and unreported

Around this time, the terminology of informal employment (feizhengui jiuye) entered the policy discourse, largely through the activities of donors, such as the ILO. ${ }^{7}$ Academics were slow to take up these issues, while the government deliberately adopted the preferred term of 'flexible' employment (linghuo jiuye) rather than the more negative sounding term 'informal' to refer to such part-time, often low paid and unprotected work. In comparison with the reforms in Latin America described as 'flexibilisation at the margins' (Tokman, this IDS Bulletin) restructuring was radical, but was presented as a way to create a more flexible and competitive labour market which would be in the long-term interests of workers (Solinger 2002: 313). The degree of informalisation of labour, and the multiple forms of informality in terms of work conditions and employment relations, emerging from this process remains an under-researched area.

\section{Analysing the labour market in China: stylised} fact or 'theoretical make-believe'?'

As is clear from the above discussion, the first three decades of reform gave rise to diverse forms of economic activity which could well be described as 'informal'. These however remained largely invisible in terms of official policy discourse, statistical data and academic analysis. Why has the notion of informality received so little attention (until recently) in China? To some extent, as implied in the preceding discussion, this lack of recognition was a political issue. The multiple challenges posed by labour market changes in a transitional economy included the threat to the political legitimacy of the 'workers' state', the ideological difficulty for the Communist Party in 
accepting rapid private sector growth; and the adaptation of a relatively inflexible administrative system to these new realities. Two further explanations are suggested here, arising from theoretical approaches to the analysis of labour markets, and the inability to capture in existing statistics these new employment forms and categories. Together, the limits of theory and empirical analysis create a gap between the frameworks or 'models' and the reality.

In terms of the theoretical constructs or models of the labour market, two main economic approaches have dominated the analysis of labour markets in developing countries, and this applies equally to China. In a brief and simplified characterisation, we sketch two frameworks broadly reflecting the approaches of development and labour economists.

Development economists building on Lewis's initial insights tend to focus on China's structural transformation and the transfer of its vast supply of 'surplus' labour from agricultural to non-agricultural activities. At an aggregate level, economic restructuring has involved a rapid shift of labour out of low productivity agriculture, where marginal returns are close to zero, into higher productivity work: first off the land into off-farm rural employment and TVEs, and subsequently out of the countryside and into the cities. This analysis is linked to a particular view of modernity through which industrialisation and the growth of manufacturing will provide jobs to absorb the rural labour force, putting countries on a path towards capital accumulation, investment and development. Such processes provide a major impetus for labour market transformation, as well as for deeper social and economic change in 'real' markets, and improvements in incomes, consumption and wellbeing.

The development literature on structural transformations in other parts of the world since the 1970s has tended to incorporate some analysis of informal employment as part of this process. The 'dualist' or sectoral perspective has portrayed informal employment as a stepping stone on the route towards more formal, 'modern' jobs, even while scholars have debated the function of such employment (as safety net, transitional mechanism, or subsidy to the formal capitalist sector). In China, the language of 'informality' in employment was never part of this discussion. Instead, a multitude of employment types emerged: household sidelines and individual household production (getihu), TVEs under collective or quasi-private 'red-hat' ownership; small private enterprises (siying qiye), etc. These activities and their related employment arrangements and relationships pushed at the limits of state sanctioned activity, but the state found ways to embrace some of them, gradually regulating and legitimising them, or incorporating them within law and policy. Communist ideology and state control however, meant there was little space for activities which fell outside acceptable definitions, but which continued to exist at the boundaries of formal, sanctioned activity. ${ }^{9}$

More significantly, this literature on China was dominated both from academic and policy perspectives by the more deeply entrenched institutional dualism of Chinese society - the rural-urban divide. A huge body of research, policy and more recently activism has been devoted to migration, the 'floating population' (liudong renkou) and rural workers in the cities (nongmin gong) by development economists and other social scientists. Since the early 1990 s, a large literature has developed as researchers explored the numbers involved, who was moving, why; for what kind of work; and with what implications for receiving and sending areas, and for the individuals and their families. ${ }^{10}$ Development economists have focused mainly on the structural economic and demographic transformations associated with this change, and the obstacles created in particular by the household registration (hukou) system. The rural-urban division has thus been more significant than the informal-formal distinction in the Chinese context.

The second major approach in the literature has been the work of a group of applied labour economists who have analysed the evolution of China's labour market since the 1980s as the system of labour allocation was relaxed, wage and price reforms and some degree of managerial autonomy over employees were introduced, and more diverse forms of ownership developed. A rich body of literature has emerged in this vein, essentially exploring a central question of how far China's system of labour allocation and the rewards to labour has moved towards a neoclassical, competitive 'labour market'? Micro-econometric analyses have examined the allocation of labour, productivity and rewards, and returns to education and human capital. By examining labour in different types of activity, enterprise and ownership type, scholars have been 
able to trace changes towards a more competitive labour market in which the role of social networks and political connections have diminished, and education and skills are increasingly rewarded, and productivity has increased. Overall, with some variation in results depending on available data, the story presented is of a trajectory from allocated labour with low productivity and few rewards to one increasingly responsive to market signals and incentives, with greater rewards to education (although evidence is mixed), and in which workers have greater mobility to move to jobs in which they are most productive. ${ }^{11}$

While these two approaches help to understand major changes occurring within the Chinese economy, the limits to these analyses are apparent when we consider the question of 'transition to what'? The 'stylised' perfectly competitive market of neoclassical economics is nowhere reality (Heintz, this IDS Bulletin) The institutional underpinnings of real markets have tended to be neglected features of these analyses often the unexplained residual or evidence of market imperfections or failure. There is inadequate attention to the distributional impacts: 'losers' are those who lack the human capital or other characteristics that enable them to compete in the market. Unexplained biases, such as lower pay or reduced labour force participation of women, are usually seen as 'discrimination.' As both Heintz and Lund (this IDS Bulletin) point out, the nature of labour as a socially produced factor of production has received little attention: in the Chinese case this matters where state provided welfare including child care, health and support for the elderly have been withdrawn and replaced usually by unpaid female labour within the household. ${ }^{12}$ The political, social and institutional underpinnings and constraints on 'real' labour markets thus remain largely outside these models.

The two approaches of development and labour economists come together around the issue of migration and the effects of labour mobility. The movement of labour out of agriculture proved one of the major push factors in diversifying employment types and creating a vibrant private sector and a more competitive labour market. Currently however, the debate is shifting to the question of whether China has reached a 'turning point' in terms of the Lewis surplus labour model. By the early years of the twenty-first century, after almost a decade of stagnation in real wages, export factories in southern
China are beginning to report a shortage of certain types of labour, leading to upward pressure on wages and the movement of more factories inland. ${ }^{13}$ The unlimited rural labour supply appears to be drying up and a tighter labour market emerging.

This possibility raises questions about the directions of further labour market developments, including the implications for wage levels, working conditions and labour protection, for the continued creation of low wage jobs producing for global markets, and for the level and nature of formal or informal employment.

\section{Data and measurement: how big is informal employment in China?}

A second reason for the invisibility of informal employment in debates in China arises from the nature of the statistics collected, which do not allow for easy identification of work types that do not fit the 'standard' definitions. ${ }^{14}$ This section briefly reviews the methods and data used, and their limitations.

At an aggregate level, the main approach for calculating the extent of informality in the urban labour force is a 'residual' method, which estimates the difference between the total labour force (based on census and labour force survey data) and the administrative reporting by enterprises of 'formal' employees. In the mid-1990s, just before enterprise restructuring started, urban employment was approximately 190 million, of which 144 million were state employees, 13.7 million formal private sector employees, and the remaining 32.6 million could then be classified as 'informal'. It was in 1998 that the start of the decline in reported employees was seen. By 2004, state sector employees were reduced by half (to 78 million), registered ('formal') private sector was 61.3 million, while the total urban employment had increased to around 265 million, leaving approximately 125 million (over 50 per cent) loosely classified as 'informal' (NBS 2005; World Bank 2007).

A second method, using sample survey data, uses the specific characteristics of jobs to estimate the level of informality. Various datasets have been used to generate results also in the region of 50 per cent of urban employment, and 80-85 per cent of migrant employment (Wu and Cai 2006; Cai et al. 2006). These sources may potentially yield the most accurate results depending on the data. Current data sets are limited in the questions they have asked, and 
risk tautology in that informality is defined in terms characteristics available in the data (most commonly the lack of a contract and social security coverage). Given the transitional nature of China's employment and social security system, these variables may not be accurate indicators of the precarious type of jobs of most concern; they may include white collar professionals; while information about some of the most precarious forms of work, or activities of the most vulnerable people, may be excluded from survey data. Thus biases could be in either direction.

In general however, this combination of conceptual and measurement problems make it impossible to understand the precise nature of the jobs, work conditions and social protection status of many of these workers. The residual approach captures a range of 'non-standard' forms of employment, which may be 'informal' to the extent that they do not conform to certain definitions and legal requirements, but may not be precarious, insecure or poorly paid. An increasing number of private sector professionals working individually as consultants for example may fall into these categories. $A$ further limitation of much data on employment - and one that is not easily overcome, is the issue of adequately capturing migrant employment in urban surveys. As migrants predominate in informal jobs and precarious forms of work this is potentially an important source of bias. From a policy perspective, and for understanding the relationship between informality, poverty and welfare, we need more finely tuned ways of disaggregating employment types. Overall, a clearer conceptualisation of the issues, improved definitions and better designed survey instruments are needed in order to measure and analyse the issues of concern for policy. More recent data collected by the NBS (including the 2005 1 per cent population survey and revised labour force surveys) have followed ILO standards for questions on employment and may allow for more robust and comparable statistics.

\section{Real markets, institutions and informal employment}

Given the conceptual and methodological limitations described above, how should we attempt to understand the informalisation of labour in China, and what research gaps need to be filled?

For socialist states, creating market-based systems entails large and politically difficult adjustments of institutions, including the structure of economic production and the distribution of benefits to workers. These changes impact on the daily lives and livelihoods of tens of millions of Chinese workers. The re-negotiation of social contracts associated with this transition, and the reconfiguration of relations between state, household and market, are all part of changing institutional arrangements within which real markets are embedded. In such contexts, social factors play a role in shaping markets, in determining who moves in and out of different forms of work; and the pathways along which entry and exit take place.

In the above discussion, entry into informal work has focused first, on factors related to economic transformation and rural to urban migration, with migrant labour entering the urban workforce creating competitive pressures at least at the lower end of the income spectrum; and second, as a result of 'shock' reform measures which pushed 'formal' or protected workers in some cases into low income jobs previously done by migrants (service, petty trade, garbage collection). Another part of the story relates to growth: China's strong export growth and the demand of factories for cheap labour; rapid urbanisation and infrastructure development requiring labour in construction; and increased incomes and consumer demand resulting in an increase demand for services. Within these activities, we see different degrees of informality: the value chain for export manufacturers for example may range from formal to factory-based work with limited social protection, to informal and unprotected sub-contracting arrangements. In construction, various arrangements for 'contracting' labour through middle men or gang leaders often leave the workers vulnerable to abuse even to the extent of not being paid or becoming essentially bonded labour. In the service sector conditions of employment tend to be insecure and unprotected. The nature of 'precarious' work - as in most contexts, thus ranges along a spectrum with the least visible 'workers' (engaged in activities that may not even be thought of as 'work') generally being the most vulnerable.

The degree of vulnerability faced by such workers is constructed both by the work they do, and by their status. Migrants are particularly vulnerable as they lack 'citizenship' status and rights in their place of work, have limited, if any claims to social protection 
from the local authorities and few mechanisms of recourse. Changes in the hukou arrangements and efforts to extend social insurance programmes may shift the problem from that of 'migrants' to one of the nature of employment. However, mechanisms for enforcement of standards set out in labour and other laws will take time to take effect.

Another way of defining informality, or of understanding entry into the 'sector', is in terms of degrees of regulation and legality - as a 'choice' to avoid burdensome regulations or taxation. Informality may also arise in the absence of relevant institutions for enforcement of formal rules. In the Chinese context, there is a large volume of relevant laws on labour, often with poor enforcement. Other laws or regulations relating to registration, tax or other administrative issues may - in the absence of impartial courts or corrupt government systems lead enterprises to avoid formality and reduce their relationship with the state. Thus a variety of formal and informal institutional arrangements influence the behaviour of entrepreneurs and employers, creating varying forms of informal employment.

These examples illustrate the importance of an institutional approach that identifies the concrete realities of specific arrangements on the ground, and which allow us to understand what is happening to informal employment during a process of rapid structural transformation; such analysis may in turn help us to better understand institutional dynamics underpinning market development. Questions should focus on understanding the different logics behind informality of employment (e.g. subsistence or survival; maximising returns; shifting costs and risks (from formal businesses) or avoiding legal obligations). Such an approach would also call for understanding both formal institutions as well as the range of non-state and informal institutions or forms of regulation which shape labour relations and outcomes. Closely linked to the discussion of institutions is an issue of the role of governments in regulating the economy, when it chooses to intervene and enforce, and for what reasons.

\section{Conclusions - the persistent puzzle of informality}

In conclusion, we are left with the puzzle of how to think about informalisation of employment in the Chinese context: is it evidence of a better functioning, more competitive labour market? Or is it instead the emergence of something dysfunctional or pathological? Or is it yet another phase in an ongoing process of transition (to what)? In some parts of the literature it is interpreted as evidence of greater competition, economic dynamism and the source of job creation (World Bank 2007); in which case, how much 'informal' (flexible, unregulated and unprotected) employment is acceptable? Alternatively, it is presented (particularly by policymakers) as something undesirable, to be regulated and formalised. Given that the state socialist system has been rejected as inefficient, the capitalist market system does not yet function, and the 'real markets' of informal institutions and allocative mechanisms are seen as in some way dysfunctional, what would the institutional arrangements for an acceptable wellfunctioning labour market, with some level of labour protection, look like?

This raises a further question: how useful is the concept of informal employment in such a context? One argument is that it is not helpful: the conditions of 'formality' (or excessive regulation) have been undermined and eroded to such an extent that the dualism implied by the terminology is irrelevant; it lacks predictive or explanatory power - it describes but does not explain. Nonetheless, informality remains a useful concept or category for making visible hidden areas of the economy and labour market. While it may have limited utility as an analytic construct, it is helpful at a descriptive level. It provides a way to distinguish certain features (though hiding others). The issue is to refocus on what is of concern, and what can/should be done about it. Going beyond the terminology, we need to recognise and understand real phenomenon in the economy, including the role of social structures and institutions. In the Chinese context, it is necessary for example to distinguish between the very different pathways into informality, and different outcomes, for migrants as opposed to urban laid-off workers.

Informal employment thus challenges 'mainstream' economics: its size and more significantly, continued growth contradict the predictions of mainstream economic analysis. It has many manifestations and functions: from more to less productive activity; from acting as a 'safety net' during economic downturn to a driver of growth in rapidly expanding economies; it is located throughout the economy - in areas thought of as 'formal', such as modern factories and industrial clusters, as well as in more traditional and 
marginal sectors. These realities challenge fundamental ideas about development, labour markets and appropriate macro economic policies. They also have wide implications for regulatory regimes including tax and social security systems.

In the context of globalisation, rapid growth and continued informalisation, it seems that the kind of jobs and welfare provisions aspired to as part of the 'modern' sector of developed economies may no longer be a realistic aspiration, or necessarily an accepted part of the social contract at the state level.

\section{Notes}

1 An extensive literature has emerged around labour rights, social security and protest in the context of state sector restructuring; see for example Chan (2001); Lee (2007a,b); Solinger (2002) and Tang (2007), among others.

2 Agricultural employment declined from 70 per cent of the total in 1978 to approximately 45 per cent by 2005 (World Bank 2007).

3 Personal discussions, Beijing 2005.

4 For details of these transitional measures, see for example Cook (1999), Solinger (2002).

5 For details, see Cook (2002) and Tang et al. (2000)

6 Results from a major survey of unemployment in 66 cities by MOLSS in 1999 were not released, and the data has not been fully analysed, due in part to sensitivity over the high levels of unemployment found.

7 The ILO-Socio-Economic Security project had a component in China.

8 As discussed by Heintz, in this IDS Bulletin

9 Some comparisons may be possible here with the barely recognised world of informal finance

\section{References}

Cai, F., Yang, D. and Wang, M. (2006) 'Marketization and/or Informalization? New Trends of China's Employment in Transition', mimeo, Institute of Population and Labor Economics, Chinese Academy of Social Sciences, Beijing

Cook, S. (2002) 'From Rice Bowl to Safety Net: Insecurity and Social Protection During China's Transition', Development Policy Review 20.5: 615-35

Cook, S. (1999) 'Readjusting Labour: Enterprise Restructuring, Social Consequences and Policy Responses in Urban China', in M. Warner (ed.),
The Chinese government has accepted flexible employment (a term sometimes used interchangeably with informal) as a policy objective, part of the process of creating a more efficient labour market; at the same time it remains uneasy about informal employment, wanting to organise and in some way formalise it, creating regulations which in turn provide incentives for employers to retreat into informality. The problem remains that creating an 'efficient' market for labour as a commodity sits uncomfortably with the overriding political objectives of a stable and 'harmonious' society.

which, as documented in detail by Tsai (2002), was critical to the growth of the private sector.

10 There is an extensive literature on migration issues: see World Bank 2007 for a recent review.

11 Some of the key works or authors have been Knight and Song (2005); Xin Meng (2000), and work by Cai Fang and colleagues at CASS, including Cai et al. 2006.

12 See, for example MacPhail and Dong 2007 and other articles in the Journal of Feminist Economics, volumes 13 and 14, 2007.

13 Work by economists at CASS, such as Cai et al. 2006 have presented this argument; see also 'Last call for Guangdong shoemakers', Asia Times online, www.atimes.com (accessed: 5 February 2008).

14 Similar problems are also evident around estimates of China's unemployment rate: see for example Giles et al. (2005) and Solinger (2001).

Changing Workplace Relations in the Chinese Economy: Beyond the Iron Rice Bowl, London: Macmillan

Cook, S. and Jolly, S. (2000) Unemployment, Poverty and Gender in Urban China: Perceptions and Experiences of Laid-off Workers in Three Chinese Cities, IDS Research Report 50, Brighton: IDS

Giles, J., Park, A. and Zhang, J. (2005) 'What is China's True Unemployment Rate?', Chino Economic Review 16: 149-70

Knight, J. and Song, L. (2005) Towards a Labour Market in China, New York: Oxford University Press 
Lee, C.-K. (2007a) 'Mapping the Terrain of Chinese Labor Ethnography', in C.-K. Lee (ed.), Working in China: Ethnographies of Labor and Workplace Transformation, London: Routledge

Lee, C.-K. (2007b) Against the Law: Labor Protests in China's Rustbelt and Sunbelt, Berkeley, Los Angeles, $\mathrm{CA}$ and London: University of California Press

MacPhail, Fiona and Dong, Xiao-yuan (2007) 'Women's market work and household status in rural China: Evidence from Jiangsu and Shandong in the late 1990s', Feminist Economics 13(3,4): 93-124

Meng, X. (2000) Labour Market Reform in China, Cambridge: Cambridge University Press

National Bureau of Statistics of China (2005) Statistical Yearbook of China, Beijing: NBS

Polanyi, Karl (1957) The Great Transformation: The Political and Economic Origins of Our Time, Boston: Beacon Press

Solinger, D.J. (2002) 'Labour Market Reform and the Plight of the Laid-off Proletariat', The China Quarterly 170: 304-26

Solinger, D.J. (2001) 'Why We Cannot Count the "Unemployed"', The China Quarterly 167: 671-88
Tang, J., Cook, S., Ren, Z. and L. Wang (2000) Chengshi Pinkun Wenti yu Zuidi Shenghuo Baozhang Zhidu Yanjiu Baogao, Research Report on urban poverty problems and the minimum livelihood security system, Beijing: CASS

Tang, J., Dong, M. and Dunda, M. (2007)

'Marginalisation of Laid-off State-owned Enterprise Workers in Wuhan', in H. Zhang, B. Wu, et al. (eds), Marginalisation in China: Perspectives on Transition and Globalisation, Aldershot: Ashgate

Tsai, K. (2002) Back Alley Banking - Private Entrepreneurs in China, Cornell: Cornell University Press

World Bank (2007) China's Modernizing Labour Market: Trends and Emerging Challenges, Synthesis Report for China Labor Market AAA Program, August, East Asia and Pacific Region

Wu, Y. and Cai, F. (2006) 'Informal Employment in Urban China: Size and Characteristics', mimeo, CASS, IPLE 